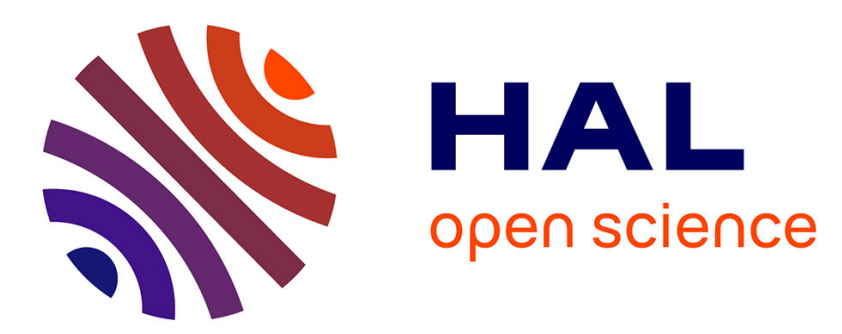

\title{
Exchange-rate return predictability and the adaptive markets hypothesis: Evidence from major foreign exchange rates
}

\author{
Amélie Charles, Olivier Darné, Jae H. Kim
}

\section{- To cite this version:}

Amélie Charles, Olivier Darné, Jae H. Kim. Exchange-rate return predictability and the adaptive markets hypothesis: Evidence from major foreign exchange rates. Journal of International Money and Finance, 2012, 31 (6), pp.1607-1626. 10.1016/j.jimonfin.2012.03.003 . hal-00958288

\section{HAL Id: hal-00958288}

\section{https://hal-audencia.archives-ouvertes.fr/hal-00958288}

Submitted on 29 Apr 2015

HAL is a multi-disciplinary open access archive for the deposit and dissemination of scientific research documents, whether they are published or not. The documents may come from teaching and research institutions in France or abroad, or from public or private research centers.
L'archive ouverte pluridisciplinaire HAL, est destinée au dépôt et à la diffusion de documents scientifiques de niveau recherche, publiés ou non, émanant des établissements d'enseignement et de recherche français ou étrangers, des laboratoires publics ou privés. 


\title{
Exchange-Rate Return Predictability and the Adaptive Markets Hypothesis: \\ Evidence from Major Foreign Exchange Rates
}

\author{
Amélie CHARLES* \\ Audencia Nantes, School of Management \\ Olivier DARNÉ ${ }^{\dagger}$ \\ LEMNA, University of Nantes \\ Jae H. KIM \\ School of Economics and Finance, La Trobe University
}

April 29, 2015

\footnotetext{
${ }^{*}$ Audencia Nantes, School of Management, 8 route de la Jonelière, 44312 Nantes Cedex 3. Email: acharles@audencia.com.

${ }^{\dagger}$ LEMNA, University of Nantes, IEMN-IAE, Chemin de la Censive du Tertre, BP 52231, 44322 Nantes, France. Email: olivier.darne@univ-nantes.fr.

¥School of Economics and Finance, La Trobe University, VIC 3086, Australia. Email: J.Kim@latrobe.edu.au.
} 


\begin{abstract}
This study examines return predictability of major foreign exchange rates by testing for martingale difference hypothesis (MDH) using daily and weekly nominal exchange rates from 1975 to 2009. We use alternative MDH tests for linear and nonlinear dependence, which include wild bootstrap automatic variance ratio test, generalized spectral test, and consistent tests. We evaluate timevarying return predictability by applying these tests with fixed-length moving sub-sample windows of two years. While exchange rate returns are found to be unpredictable most of times, we do observe episodes of statistically significant return predictability. They are associated with coordinated central bank interventions and the subprime mortgage crisis in 2007. This finding suggests that return predictability of foreign exchange rates occurs from time to time depending on changing market conditions, which is consistent with the implications of the adaptive markets hypothesis.
\end{abstract}

Keywords: Adaptive markets hypothesis; martingale difference hypothesis; variance ratio test; spectral test.

JEL Classification: G14; G15; C12; C14. 


\section{Introduction}

One of the earliest and most enduring questions in economics and finance is whether prices of financial assets are predictable. The efficient market hypothesis (EMH) of Samuelson (1965) and Fama (1965) states that asset prices fully and instantaneously reflect all available and relevant information. Since price adjustment to a new piece of information is instantaneous and accurate, the returns cannot be predicted. As a result, prices in an efficient market follow a random walk or a martingale process. ${ }^{1}$ Under the weak-form efficiency where the information set consists of past prices and returns, future prices and their returns are purely unpredictable based on past price information. Most of the studies for the EMH on financial markets have tested whether the returns follow a martingale difference sequence (MDS), where the returns are uncorrelated with the past values. If the foreign exchange market is weak-form efficient, the nominal exchange rate follows a martingale sequence and its returns are purely unpredictable based on past price and return information. For these reasons, the return predictability has been an important issue related to the market efficiency in the weak form.

There are several alternatives explanations for predictability in foreign exchange markets: (i) the prices in these markets do not quickly adjust to the new information (Fama, 1970; Melvin, 2004); (ii) the exchange rates are not set at the equilibrium level due to distortions in the pricing of capital and the valuing of risk (Smith et al., 2002); (iii) the emergence of a parallel/black market due to the existence of the exchange rate controls and resulting divergence between the equilibrium rate and the official rate (Diamandis et al., 2007); (iv) the exchange rate regime and regulatory arrangements, as they may affect the degree of foreign banks to access the foreign exchange markets and products; (v) the overshooting or undershooting phenomenon of exchange rates (Liu and He, 1991); and (vi) the central bank intervention (Dominguez and Frankel, 1993; Yilmaz, 2003; Beine et al., 2009). ${ }^{2}$

There have been numerous studies that tested the MDH in major foreign exchange rates. Since Meese and Rogoff (1983) showed that the structural models of exchange

\footnotetext{
${ }^{1}$ See Escanciano and Lobato (2009b) for a distinction between random walk and martingale process.

${ }^{2}$ Note that no consensus has been reached on the effect of central banks intervention. For some, the impact of intervention vanishes after a few minutes or a day (Dominguez, 2006). For others, it lasts several days or weeks (Fratzscher, 2006). Yilmaz (2003) and Szakmary and Mathur (1997) document that exchange rates can deviate from the martingale property and produce profitable trading returns during times of coordinated central bank interventions. On the other hand, Neely (2002) provides evidence that central bank intervention does not generate technical trading profits. See Menkhoff (2010) for a discussion on foreign exchange interventions.
} 
rate determination provide inferior out-of-sample forecasts to those implied by a MDS, many studies strived to uncover the empirical regularities in exchange rate behavior. In the literature, several alternative methods have been used to test for martingale behavior, including autocorrelation tests (Box and Pierce, 1970; Ljung and Box, 1978), variance ratio tests (Lo and MacKinlay, 1988, 1989), and spectral tests (Durlauf, 1991; Hong, 1996) and their improved modifications. ${ }^{3}$ These methods have been used in many empirical applications on foreign exchange rates: see Hsieh (1988), Liu and He (1991), Fong et al. (1997), Wright (2000), Lobato et al. (2001), Yilmaz (2003), Kuan and Lee (2004), Escanciano and Velasco (2006) and Escanciano and Lobato (2009a, 2009b), among others. However, the results are overall mixed and scattered over numerous studies that use different sample periods (often outdated), methods (often one type of methodology) and data frequencies (weekly or daily).

Recently, Lo (2004, 2005) proposed the adaptive markets hypothesis (AMH), which gives a framework to reconcile the EMH with the notion of bounded rationality. ${ }^{4}$ An important implication of the AMH is that return predictability may arise time to time, due to changing market conditions (cycles, bubbles, crashes, crises, ...) and institutional factors. For the foreign exchange markets, a number of studies found that changing market conditions, caused by the events such as coordinated central bank intervention (LeBaron, 1999; Jeon and Lee, 2002; Yilmaz, 2003), Asian financial crisis (Jeon and Seo, 2003; Ahmad et al., 2011; Al-Khazali et al., 2011, 2012), and the global financial crisis (Ahmad et al., 2011), can affect market efficiency and other market features. These events have strong implications for the psychology of market participants and the way they incorporate new information to prices, which in turn may generate time variation in serial correlation of returns. In view of Lo's $(2004,2005)$ $\mathrm{AMH}$, it is highly likely that the degree of return predictability is driven largely by such dynamic market conditions.

\footnotetext{
${ }^{3}$ See Escanciano and Lobato (2009b) for a discussion on testing the MDH.

${ }^{4}$ The AMH is developed by coupling the evolutionary principle with the notion of bounded rationality (Simon, 1955). A bounded rational investor is said to exhibit satisfying rather than optimal behavior. Optimization can be costly and market participants with limited access to information or abilities to process information are merely engaged in attaining a satisfactory outcome. Lo $(2004,2005)$ argues that a satisfactory outcome is attained not analytically, but through an evolutionary process involving trial error and natural selection. The process of natural selection ensures the survival of the fittest and determines the number and composition of market participants. Market participants adapt to constantly changing environment and rely on heuristics to make investment choices (Kim et al., 2011). Based on the evolutionary perspective, profit opportunities do exist from time to time. Though they disappear after being exploited by investors, new opportunities are continually being created as groups of market participants, institutions and business conditions change.
} 
Lim and Brooks (2010) reviewed the studies for time-varying weak-form market efficiency in stock returns and categorized them into three approaches: (i) nonoverlapping sub-period analysis, (ii) time-varying parameter model, and (iii) rolling estimation window. In this study, we use the approach of moving sub-sample window to capture the dynamically changing return predictability under the AMH. To the best of our knowledge, Yilmaz (2003), Chiang et al. (2010), Belaire-Franch and Contreras (2011), and Chuluun et al. (2011) are the only studies that evaluate the MDH using time-varying measures in foreign exchange rates, but without an explicit link with the $\mathrm{AMH}$

The aim of this paper is to evaluate the evolution of return predictability of the major foreign exchange rates and to examine whether its evolution is consistent with the AMH. This study is based on an extensive sample of daily and weekly data for major foreign exchange rates over the period 1974-2009, which cover the periods of major coordinated central bank interventions and financial crises. We measure the degree of return predictability using three alternative tests for the $\mathrm{MDH}$, namely the wild bootstrap automatic variance-ratio test of Kim (2009), the generalized spectral shape test of Escansiano and Velasco (2006), and the consistent tests of Dominguez and Lobato (2003). These tests are capable of detecting linear and nonlinear dependence, being robust to non-normality and conditional heteroscedasticity that are typical features of foreign exchange rates (see, for details, Charles et al.; 2011).

The remainder of this paper is organized as follows: Section 2 presents the alternative tests for the MDH adopted in this paper with a survey of the tests used in previous studies; Section 3 provides the details of the data and reports the empirical results, along with a brief survey of past empirical studies. Section 4 provides further discussions and the conclusion is drawn in Section 5.

\section{Tests for Martingale Difference Hypothesis}

\subsection{A Brief Survey of the Tests}

In testing for market efficiency or return predictability, the variance ratio (VR) test has been widely used. Since Lo and MacKinlay (1988) propose its original version, the test has undergone a number significant improvements, including the multiple variance ratio test of Chow and Denning (1993), sign and rank tests of Wright (2000), and wild bootstrap test of Kim (2006). ${ }^{5}$ The test is based on the property that, if return

\footnotetext{
${ }^{5}$ See Hoque et al. (2007) and Charles and Darné (2009a) for a review on the VR tests.
} 
is purely random, the variance of $k$-period return is $k$ times the variance of the oneperiod return. Hence, the variance ratio $V R(k)$, defined as the ratio of $1 / k$ times the variance of $k$-period return to that of one-period return, should be equal to one for all values of $k$. To implement the test, one should test for the null hypothesis that the VR is equal to one for a set of (holding periods) $k$ values. For example, popular choices in empirical applications include $k \in\{2,5,10,30\}$ for daily return, while $k \in\{2,4,8,16\}$ for weekly return (see, for example, Belaire-Franch and Opong, 2005; and Fong et al., 1997). However, these choices are entirely arbitrary and adopted without any concrete statistical justifications. In view of this, Choi (1999) proposes an automatic variance ratio (AVR) test, in which the optimal value of holding period $k$ is determined automatically using a completely data-dependent procedure. In a recent study, Kim (2009) evaluates Choi's (1999) test under conditional heteroscedasticity and has found that the test shows size distortion. Kim (2009) proposes wild bootstrapping of the test, which significantly improves the size and power properties of the test. In addition, this wild bootstrap AVR test compares favorably to the other alternatives such as the wild bootstrap (Chow-Denning) test of Kim (2006), the power-transformed test of Chen and Deo (2006) and the joint sign test of Kim and Shamsuddin (2008), where the choice of holding periods is arbitrarily made.

An alternative test for return predictability based on serial correlation of return is the portmanteau test of Box and Pierce (1970) and Ljung and Box (1978). Although a few early papers on testing for weak-form market efficiency adopt this test, it has been largely neglected in the market efficiency literature. This is mainly because of the well-known fact that the Box-Pierce and Ljung-Box portmanteau tests suffer from low power and that they are valid under a restrictive condition that the returns are identically and independently distributed. Recently, a series of papers propose modified portmanteau tests applicable to return under more general conditions allowing for unconditional or conditional heteroscedasticity, which include Lobato et al. (2001, 2002) and Escanciano and Lobato (2009a). In particular, Escanciano and Lobato (2009a) propose an automatic portmanteau test in which the optimal lag order is selected using a fully data dependent procedure. Escanciano and Lobato (2009a) report that their automatic test shows desirable small sample properties such as correct size and high power, under conditional heteroscedasticity. They also find that it is more powerful than the robustified tests of Lobato et al. (2001, 2002), where the choice of lag order is arbitrarily made.

Andrews and Ploberger (1996) propose another approach to testing for serial correlation, which is designed for the time series generated by an $\operatorname{ARMA}(1,1)$ model 
under the alternative hypothesis. Recently, Nankervis and Savin (2010) generalize the Andrews-Ploberger tests when the time series is serially uncorrelated but statistically dependent, in the same approach used by Lobato et al. (2002) to the generalization of the Box-Pierce test. They find that their generalized Andrews-Ploberger tests have satisfactory power properties compared to the generalized Box-Pierce test and the Deo (2000) tests.

The above-mentioned tests are (linear) autocorrelation-based tests, which are designed to capture the linear dependence of return on its own past. However, given the evidence of non-linear dependence in asset returns, evaluation of linear dependence only may be restrictive. The generalized spectral shape test of Escanciano and Velasco (2006) is capable of detecting possible non-linear dependence in returns. This test can capture a wide range of linear and non-linear dependence in mean, allowing for a general form of unknown conditional heteroscedasticity in variance. According to the Monte Carlo experiment of Escansiano and Velasco (2006), the test is more powerful than its competitors such as Deo (2000), Domínguez and Lobato (2003), Kuan and Lee (2004) and Hong and Lee (2003, 2005).

Recently, Charles et al. (2011) conduct an extensive Monte Carlo experiment to find that the wild bootstrap AVR test of Kim (2009), the generalized spectral shape (GSS) test of Escansiano and Velasco (2006) and the consistent test of Domínguez and Lobato (2003) (called DL hereafter) give higher power against a wide range of linear and non-linear models, with no size distortion, than the automatic portmanteau test of Escanciano and Lobato (2009a). More precisely, the AVR test shows the highest power against linear dependence; while the GSS and DL tests perform most desirably under nonlinear dependence. These tests are also robust to non-normality and unknown forms of conditional and unconditional heteroscedasticity. In the next subsections, we present the details of these three tests, which are adopted in this paper.

\subsection{Automatic variance ratio test}

Let $Y_{t}$ denote asset return at time $t$, where $t=1, \ldots, T$. Choi's (1999) AVR test is based on a variance ratio estimator related to the normalized spectral density estimator at zero frequency. Namely,

$$
\widehat{V R}(k)=1+2 \sum_{i=1}^{T-1} k(i / k) \widehat{\rho}(i),
$$

where $\hat{\rho}(i)=\hat{\gamma}(i) / \hat{\gamma}(0)$ is the sample autocorrelation of order $i, \hat{\gamma}(i)$ is the sample autocovariance of order $i$, and 


$$
k(x)=\frac{25}{12 \pi^{2} x^{2}}\left[\frac{\sin (6 \pi x / 5)}{6 \pi x / 5}-\cos (6 \pi x / 5)\right],
$$

is the quadratic spectral kernel. According to Choi (1999), under the condition that $Y_{t}$ is an i.i.d. sequence with finite fourth moment,

$$
A V R(k)=\sqrt{T / k}[\widehat{V R}(k)-1] / \sqrt{2} \rightarrow_{d} \mathbf{N}(0,1),
$$

as $T \rightarrow \infty, k \rightarrow \infty$, and $T / k \rightarrow \infty$. To test for $H_{0}: V R(k)=1$, a choice for the value of lag truncation point $k$ should be made, which is equivalent to the value of holding period in the time domain. Choi (1999) proposes a data-dependent method of choosing $k$ optimally, following Andrews (1991), noting that this choice may exert an enormous impact on the variance ratio test. The $A V R$ test statistic with the optimally chosen lag truncation point is denoted as $A V R\left(k^{*}\right)$; Choi (1999) notes that $k^{*}$ chosen by Andrews' (1991) method satisfies the conditions related to (2).

Kim's (2009) wild bootstrap AVR test is conducted in three stages as follows:

1. Form a bootstrap sample of size $T$ as $Y_{t}^{*}=\eta_{t} Y_{t}(t=1, \ldots, T)$ where $\eta_{t}$ is a random variable with zero mean and unit variance;

2. Calculate $A V R^{*}\left(k^{*}\right)$, the $A V R\left(k^{*}\right)$ statistic calculated from $\left\{Y_{t}^{*}\right\}_{t=1}^{T}$;

3. Repeat 1 and $2 B$ times, to produce the bootstrap distribution of the $A V R$ statistic $\left\{A V R^{*}\left(k^{*} ; j\right)\right\}_{j=1}^{B}$.

The test for $H_{0}$ against the two-tailed alternative is conducted to using the $p$-value, which is estimated as the proportion of the absolute values of $\left\{A V R^{*}\left(k^{*} ; j\right)\right\}_{j=1}^{B}$ greater than the observed statistic $A V R\left(k^{*}\right)$.

\subsection{Tests based on nonlinear measures of dependence}

Suppose $Y_{t}$ follows a martingale difference sequence, and the null hypothesis of interest is $H_{0}: E\left(Y_{t} \mid Y_{t-1}, Y_{t-2}, \ldots\right)=\mu$, where $\mu$ is a real number. Escansiano and Velasco (2006) express the above null hypothesis in a form of pairwise regression function. That is, $H_{0}: m_{j}(y)=0$, where $m_{j}(y)=E\left(Y_{t}-\mu \mid Y_{t-j}=y\right)$, against $H_{1}$ : $P\left[m_{j}(y) \neq 0\right]>0$ for some $j$. Escansiano and Velasco (2006) note that the above null hypothesis is equivalent to the following condition:

$$
\gamma_{j}(x) \equiv E\left[\left(Y_{t}-\mu\right) e^{i x Y_{t-j}}\right]=0,
$$


where $\gamma_{j}(x)$ represents an autocovariance measure in a non-linear framework and $x$ represents any real number. Escansiano and Velasco (2006) propose the use of the generalized spectral distribution function

$$
H(\lambda, x)=\gamma_{0}(x) \lambda+2 \sum_{j=1}^{\infty} \gamma_{j}(x) \frac{\sin (j \pi \lambda)}{j \pi},
$$

where $\lambda$ is any real number in $[0,1]$. The sample estimate of the above distribution function is written as

$$
\widehat{H}=\widehat{\gamma}_{0}(x) \lambda+2 \sum_{j=1}^{\infty}\left(1-\frac{j}{T}\right) \widehat{\gamma}_{j}(x) \frac{\sin (j \pi \lambda)}{j \pi},
$$

where $\widehat{\gamma}_{j}(x)=(T-j)^{-1} \sum_{t=1+j}^{T}\left(Y_{t}-\bar{Y}_{T-j}\right) e^{i x Y_{t-j}}$ and $\bar{Y}_{T-j}=(T-j)^{-1} \sum_{t=1+j}^{T} Y_{t}$. Under the null hypothesis, the above generalized spectral distribution function has the value $\widehat{H}_{0}(\lambda, x)=\widehat{\gamma}_{0}(x) \lambda$, and the statistic of interest to test for $H_{0}$ is constructed as

$$
\begin{aligned}
S_{T}(\lambda, x) & =(0.5 T)^{1 / 2}\left\{\widehat{H}(\lambda, x)-\widehat{H}_{0}(\lambda, x)\right\} \\
& =\sum_{j=1}^{T-1}(T-j)^{0.5} \widehat{\gamma}_{j}(x) \frac{\sqrt{2} \sin (j \pi x)}{j \pi} .
\end{aligned}
$$

To evaluate the value of $S_{T}$ for all possible values of $\lambda$ and $x$, Escansiano and Velasco (2006) use the Cramer-von Mises norm to yield the statistic of the form

$$
D_{T}^{2}=\int_{R} \int_{0}^{1}\left|S_{T}(\lambda, x)^{2}\right| W(d x) d \lambda=\sum_{j=1}^{T-1} \frac{(T-j)}{(j \pi)^{2}} \int_{R}\left|\widehat{\gamma}_{j}(x)\right|^{2} W(d x),
$$

where $W()$ is a weighting function satisfying some mild conditions. Using the standard normal distribution as a weighting function, Escansiano and Velasco (2006) obtain the GSS test statistic

$$
D_{T}^{2}=\sum_{j=1}^{T-1} \frac{(T-j)}{(j \pi)^{2}} \sum_{t=j+1}^{T} \sum_{s=j+1}^{T} \exp \left(-0.5\left(Y_{t-j}-Y_{s-j}\right)^{2}\right) .
$$

Dominguez and Lobato (2003) propose alternative tests based on nonlinear measure of dependence, which test for no directional predictability. Their tests (called the DL tests), based on Cramer-von Mises (CvM) and Kolmogorov-Smirnov (KS) statistics, can be written as

$$
\begin{aligned}
C v M_{T, p} & =\frac{1}{\widehat{\sigma}^{2} T^{2}} \sum_{j=1}^{T}\left[\sum_{t=1}^{T}\left(Y_{t}-\bar{Y}\right) 1\left(\widetilde{Y}_{t, p} \leq \widetilde{Y}_{j, p}\right)\right]^{2} \\
K S_{T, p} & =\max _{1 \leq i \leq T}\left|\frac{1}{\widehat{\sigma} \sqrt{T}} \sum_{t=1}^{T}\left(Y_{t}-\bar{Y}\right) 1\left(\widetilde{Y}_{t, p} \leq \widetilde{Y}_{j, p}\right)\right|,
\end{aligned}
$$


where $\widetilde{Y}_{t, p}=\left(Y_{t-1}, \ldots, Y_{t-p}\right), 1()$ is the indicator function, and $p$ is a positive integer.

The GSS and DL test statistics given in (3) to (4) do not possess the standard asymptotic distributions. To implement the tests in finite samples, the above authors recommend the use of the wild bootstrap. That is, the $p$-value of the test can be obtained from the wild bootstrap distribution, as described for the AVR test. The DL tests are conditional on finite-dimensional information set, requiring the choice of lag order $p$; while the GSS exploits infinite-dimensional information set. As noted in Escanciano and Velasco (2006), the GSS test is only pairwise consistent, but is inconsistent against pairwise MDS which are non-MDS.

\section{Empirical findings}

\subsection{Brief Literature Survey}

There have been numerous studies that tested the MDH in major foreign exchange rates with overall mixed and sometimes inconclusive results. Table ?? presents a brief summary of the selected studies, indicating the methodologies used, the types and frequencies of data employed, and the foreign exchange rates analyzed.

Liu and He (1991), Fong et al. (1997), Wright (2000), Yilmaz (2003), Chang (2004), and Belaire-Franch and Opong (2005) investigate the MDH in major exchange rates from VR tests. Liu and He (1991) apply the Lo-MacKinlay (1988) VR tests and provide evidence that the $\mathrm{MDH}$ is rejected for five major foreign exchange rates, namely Canadian dollar, French franc, German mark, Japanese yen, and British pound. Their results suggest that autocorrelations are present in weekly returns in nominal exchange rate series over the period 1974-1989. Fong et al. (1997), Wright (2000), Yilmaz (2003) and Chang (2004) re-examine the same five exchange rates using various VR tests. Wright (2000) and Yilmaz (2003) apply non-parametric sign and rank-based VR tests, Chow-Denning VR test (1993), and Richardson-Smith (1991) VR tests, confirming the results obtained by Liu and He (1991). Fong et al. (1997) find that the Richardson-Smith test fails to reject the MDH for all five currencies, whereas the Chow-Denning test continues to reject the hypothesis for the French franc, German mark, and Japanese yen. Chang (2004) provides evidence of rejecting the MDH for the Japanese yen, while the results for the other four currencies are inconclusive when daily data is employed using the Lo-MacKinlay VR test with a bootstrap resampling technique. Belaire-Franch and Opong (2005) use Wright's (2000) rank and sign VR tests, with size adjustment for multiple testing, to examine the MDH of ten daily Euro-based nominal exchange rates (Australian dollar, Canadian dollar, New Zealand 
dollar, Japanese yen, British pound, Norwegian kroner, Singapore dollar, Swedish krona, Swiss franc, and United States dollar) over the 1999-2002 period. Their results indicate that the Euro exchange rates are unpredictable and their markets are weakform efficient. Charles and Darné (2009b) and Belaire-Franch and Opong (2010) re-examine the same Euro-based exchange rates of Belaire-Franch and Opong (2005) over the 1999-2008 period and the 1999-2003 period, respectively. Charles and Darné (2009b) apply the VR tests of Belaire-Franch and Contreras (2004) and Chen and Deo (2006), whereas Belaire-Franch and Opong (2010) use VR tests based on the subsampling approach proposed by Whang and Kim (2003). They find that the these Euro exchange rates follow random walk.

Fong and Ouliaris (1995), Hong (1999), Hong and Lee (2003), Kuan and Lee (2004), and Escanciano and Velasco (2006) study foreign exchange rates using spectral tests that are capable of capturing nonlinear dependence. Fong and Ouliaris (1995) re-analyze the same five currencies of Liu and He (1991) for the same period and frequency from a family of spectrum-based tests proposed by Durlauf (1991) and reject the MDH only for the British pound. Kuan and Lee (2004) obtain the same results from their spectral test, except for the British currency for which they do not reject the MDH, whereas Hong and Lee (2003), Escanciano and Velasco (2006) and Escanciano and Lobato (2009b) reject the MDH for all exchange rates using the generalized spectral tests. This result is confirmed by Hong (1999) for the German mark on the period 1976-1995, using the generalized spectral test.

Hsieh (1988), Lobato et al. (2001), Horowitz et al. (2006), Escanciano and Lobato (2009a, 2009b), and Chortareas et al. (2010) analyze the MDH for various major exchange rates using (Box-Pierce type) autocorrelation tests. Hsieh (1988) investigates the five major currencies, daily from 1974 to 1983, using heteroscedasticity-adjusted Box-Pierce test and reject the null of the MDH. Lobato et al. (2001) use a modified Box-Pierce test using daily returns for the German mark, the Japanese yen, the Swiss franc, and the British pound to find that the MDH is not rejected for all the currencies on the period 1976-1996. Escanciano and Lobato (2009a) obtain the same results for the Canadian dollar and the Japanese yen for the period 1987-2007 using their automatic portmanteau test, whereas they reject the $\mathrm{MDH}$ for the British pound. Escanciano and Lobato (2009b) find that the Canadian dollar, Japanese yen and British pound have no linear dependence for the period 2004-2007, using a number of autocorrelation tests. This result is confirmed by Horowitz et al. (2006) for the British pound on the period 1993-1996 from a bootstrapped Box-Pierce test. Chortareas et al. (2010) study the MDH for various OECD exchange rates from generalized Andrews- 
Ploberger autocorrelation tests proposed by Nankervis and Savin (2010). The tests do not reject the MDH for most exchange rates.

Finally, Yilmaz (2003), Chiang et al. (2010), Belaire-Franch and Contreras (2011) and Chuluun et al. (2011) are the only studies that evaluate the MDH from timevarying measures using moving subsample windows. ${ }^{6}$ More precisely, Yilmaz (2003) use the VR tests of Chow-Denning (1993) and Richardson-Smith (1991); Chiang et al. (2010) use those of Lo and MacKinlay (1988), Wright (2000) and Chow and Denning (1993); while Chuluun et al. (2011) use those of Chow and Denning (1993), Lo and MacKinlay (1988), Wright (2000), along with the spectral test of Kuan and Lee (2004).

\subsection{Data and Descriptive Statistics}

We use daily nominal exchange rates, for the Australian dollar (AU\$), British pound (GBP), Canadian dollar (CA\$), Japanese yen (JPY), and Swiss franc (CHF) relative to the US dollar, which are major US dollar denominated exchange rates that are classified as independently floating by the International Monetary Fund. The data span from January 2, 1974 to July 17, 2009, with a total of 9,274 observations. We also use weekly data observed on Wednesday or on the next day if the markets are closed on Wednesday. The nominal exchange rate data are the daily noon buying rates in New York City (certified by the Federal Reserve Bank of New York for customs and cable transfers purposes), which are obtained from the Federal Reserve. ${ }^{7}$

We first present descriptive statistics for the return series calculated as the first logarithmic difference of the nominal exchange rates for daily and weekly data in Table ??. For the daily data (Panel A), in terms of standard deviation, CA $\$$ exhibits the least volatility, while CHF displays the highest volatility. On average, US\$ has depreciated against all five currencies during the data period. The Jarque-Bera test statistic is significant at the $1 \%$ level of significance for all series, indicating that the exchange returns are highly non-normal. The excess kurtosis and negative skewness values indicate that the empirical distributions of the returns exhibit substantially fatter tails (than the normal distribution) and asymmetric shape (with longer left tail). We also conduct the LM test of Engle (1982) for ARCH conditional heteroscedasticity. ${ }^{8}$ This test statistic is significant for all rates, indicating that they show strong conditional

\footnotetext{
${ }^{6}$ Yilmaz (2003), Chiang et al. (2010), Belaire-Franch and Contreras (2011), and Chuluun et al. (2010) employ fixed-length moving windows with 1,000 daily, 250 daily, 1,000 daily, and 260 weekly observations, respectively.

${ }^{7}$ The data are obtained from http://www.federalreserve.gov/Releases/h10/hist.

${ }^{8}$ The LM test is applied on the residuals of the ARMA model, where the lag length is selected based on the Akaike information criterion.
} 
heteroscedasticity. Similarly to the daily data, the weekly data (Panel B) show that all returns are non-normal with significant excess skewness and excess kurtosis, with strong evidence of conditional heteroscedasticity. As mentioned earlier, the MDH tests adopted in this paper are robust to these features.

\subsection{Evaluating time-varying return predictability}

For daily data, we use moving sub-sample window of 2 years, which consists of approximately 520 observations. This sample size is large enough to avoid possible small sample deficiencies for the tests involved. The first subsample window covers the period from January 2, 1974 to December 31st, 1975. After the tests are conducted for the first subsample, the window is moved five daily observations forward to lighten the computational burden, and the test statistics are recalculated. For the weekly data, we choose a window length of 104 weeks ( 2 years). ${ }^{9}$ We plot the $p$-values of the test statistics over time. When they are less than 0.05 or 0.10 , the return predictability is significant at $5 \%$ or $10 \%$ level of significance. In this way, the periods or episodes of statistically significant return predictability can be identified, which in turn can be related to the corresponding shocks and events.

Figures ??-?? report the $p$-values of the AVR, GSS and DL tests for the daily data, while Figures ??-?? for the weekly data. The two horizonal lines correspond to 0.05 and 0.10 . Overall, the results show that all nominal exchange rates deviate from the martingale in a number of periods. This indicates that the currencies do not follow a MDS for the entire period 1975-2009, which includes the period of Great Moderation. ${ }^{10}$ We clearly observe non-martingale episodes, which indicate periods of return predictability consistent with the implications of the AMH.

For the daily data (Figures ??-??), the three tests reject the MDH for CA $\$$ and JPY; the AVR and the DL tests also reject the MDH for AU\$ and GBP; and the AVR test rejects the MDH for CHF in 1980. The timing corresponds to the Volcker disinflationary policy period where the inflation is stabilized with several coordinated interventions of the major central banks. As the subsample window moves to 1982, all three tests reject the MDH for AU\$; the AVR test for CA\$, JPY and GBP; and the DL tests for CHF, which coincide with the timing of the intervention of the Reagan administration for concerted interventions with major central banks to slow down the

\footnotetext{
${ }^{9}$ We have also considered others window lengths for both daily and weekly data, and we found that the results are not sensitive to the different choices of window length.

${ }^{10}$ See, for example, Kim et al. (2008), Gali and Gambetti (2009), and Enders and Ma (2011) on the sources of the Great Moderation.
} 
appreciation of the dollar. Note also the abandonment of the crawling peg system for AU\$ in favor of an independently floating exchange rate in 1983, which may have affected the martingale behavior. The AVR and GSS test for CA\$, JPY and CHF; the AVR and DL tests for AU\$; and the DL test for GBP start to move to the rejection region from the end of 1985, indicating a strong deviation from martingale behavior with the coordinated intervention period that started after the Plaza Accord in September 1985. This agreement marks a drastic change in the policy stance of the major central banks in terms of the movements of exchange rates, since G7 finance ministers agreed to intervene in the worldwide foreign exchange markets in a concerted fashion when they find it necessary. Most of the concerted interventions have taken the form of selling US\$ against other major currencies (Dominguez, 1990).

As the subsample windows move forward to 1987, the AVR and DL tests reject the MDH for CA\$, JPY and GBP; and the GSS and DL tests for AU\$, with the interventions of the Louvre Accord period after February 1987. This agreement reenforces the concerted interventions of the leading central banks (US Federal Reserve, Bundesbank, and Bank of Japan) by setting unannounced and secret target bands for their exchange rates, beyond which central banks have agreed to intervene. AU\$ and GBP show a non-martingale behavior when the subsample window moves to 1995, with the coordinated interventions of the G7 central banks to help the dollar. The AVR test statistics for AU\$, CA \$ and GBP started to move to the rejection region during the 2008-2009 financial crisis period. This crisis is characterized by the massive central banks and government interventions. For example, the Bank of Canada $(\mathrm{BoC})$, the Bank of England (BoE), the European Central Bank (ECB), the Federal Reserve (Fed), and the Swiss National Bank (SNB) reduced their policy interest rates in October 2008. The SNB and ECB cooperated to provide CHF liquidity in October 2008. During the 2008-2009 period, the BoE, the ECB, the Fed, the Bank of Japan (BoJ), and the SNB took joint measures to improve liquidity in short-term US dollar funding markets, in order to provide broad access to liquidity and funding to financial institutions. $^{11}$

Note that, contrary to the findings of Yilmaz (2003), we do not find rejection of the MDH for the Gulf war period. We note that the Chow-Denning and RichardsonSmith joint tests that Yilmaz (2003) used suffer from size distortion in small samples, as documented in Kim (2006). In light of this, there is a possibility that the findings of Yilmaz (2003) may have provided incorrect inferential outcomes.

\footnotetext{
${ }^{11}$ Melvin and Taylor (2009) reviewed the events and implications of this crisis for exchange rate market, especially volatility, returns to currency investing, and transaction costs.
} 
Furthermore, a number of non-martingale periods occur specifically to particular currencies. Namely, the outbreak of the Exchange Rate Mechanism (ERM) crisis in 1992 for GBP (AVR and DL tests), after excessive speculative attacks where the BoE intervenes heavily to defend its ERM exchange rate; the Japanese recession in 1993 for JPY (DL tests), with concerned interventions of the Fed and the BoJ to support the JPY; the low interest rate policy of the $\mathrm{BoC}^{12}$ in 1996 (DL test), which leads to a rapid decline in the value of the CA\$. Other cases include the East-Asian financial crisis in 1997, which caused a drop of the AU\$ (GSS and DL tests); the intervention of the BoJ in 1999 to support the JPY (DL test); the rise of commodity prices and Canadian domestic inflation in 2004 (GSS test); and the US dollar's massive budget and current account deficits as well as the gold selling program of the SNB in 2005 caused the drop of the CHF (AVR and DL tests).

\section{Further Discussions}

In this paper, we use moving sub-sample windows to measure the degree of foreign exchange return predictability. There are two major benefits of this approach. First, it is capable of measuring time-varying return predictability, which is implied by the $\mathrm{AMH}$ where the degree of market efficiency (or return predictability) is changing over time depending on market conditions. Second, as Hsu and Kuan (2005; p.608) point out, it is a useful tool to address the problem of data snooping bias, as an effective alternative to the statistical tests of White (2000) and Hansen (2005). It should be noted that the moving sub-sample window approach is not intended for multiple testing in this paper, but as a means of measuring the degree of return predictability as stated above.

While we acknowledge that the approach we have taken is not a direct test for the $\mathrm{AMH}$, there is no formal statistical test proposed to date as a direct test for the $\mathrm{AMH}$, to the best our knowledge. We have observed that the periods of rejecting the $\mathrm{MDH}$ are closely related to the timing of major events, such as coordinated central bank interventions and financial crises (Asian and sub-prime mortgage). We argue that these major events alter the market conditions, which in turn change the degree of return predictability. Indeed, as mentioned earlier, there are accumulated evidence in the literature that these events change the conditions and ecology of foreign exchange

\footnotetext{
${ }^{12}$ Note that the BoC has no specific target value for $\mathrm{CA} \$$ and has not intervened in foreign exchange markets since 1998. The Bank's official position is that market conditions should determine the worth of CA\$.
} 
markets (see, for example, Dominguez, 1998, 2003; Le Baron, 1999; Jeon and Lee, 2002; Jeon and Seo; 2003; and Ahmad et al., 2011). Hence, while our testing procedure is not a direct test for AMH, the outcomes of our tests are highly suggestive to the implications of the AMH. Note that Neely et al. (2009) adopt a similar approach in the context of the profitability of technical trading rules.

Although multiple testing is not intended in this paper as noted above, the $p$-values reported in the previous section provide an interesting result. Under the MDH, these $p$-values should be uniformly distributed, and the probability that a $p$-value is less than 0.05 should follow a binomial distribution. ${ }^{13}$ Using a normal approximation to a binomial distribution, we can test $\mathrm{H}_{0}: q=0.05$ against $\mathrm{H}_{1}: q>0.05$, where $q$ represents the population proportion of the $p$-values less than 0.05 . Rejection of $\mathrm{H}_{0}$ in favor of $\mathrm{H}_{1}$ is evidence against the MDH. Table ?? reports the sample proportions of the $p$-values less than 0.05 for all currencies and tests. For daily data, at $5 \%$ level of significance, the null hypothesis is not rejected for most of cases; while, for weekly data, the null hypothesis is rejected for nearly all cases. This indicates that departure from the MDH is much stronger when the returns are evaluated at the weekly frequency.

\section{Conclusion}

This study examined return predictability of major foreign exchange rates by testing for martingale difference hypothesis (MDH) using daily and weekly data from 1975 to 2009. We used alternative MDH tests for linear and nonlinear dependence, which include wild bootstrap automatic variance ratio test, generalized spectral test, and Dominguez-Lobato consistent tests. We evaluated time-varying return predictability by applying these tests with fixed-length moving sub-sample windows of 2 years. While exchange rate returns have been found to be unpredictable most of times, we observed episodes of statistically significant return predictability. We found that they are closely associated with the major events such as coordinated central bank interventions and the financial crises. This finding suggest that return predictability of foreign exchange rates occurs from time to time depending on changing market conditions, which is consistent with the implications of the adaptive markets hypothesis. That is, dynamic market conditions govern the degree of

\footnotetext{
${ }^{13}$ We thank a referee for suggesting this point. We note that the validity of the binomial distribution depends on the independence of $p$-values over time, which might be questionable, as the referee pointed out.
} 
efficiency of foreign exchange markets.

\section{References}

[1] Ahmad R., Rhee S.G. and Wong Y.M. (2011). Foreign exchange market efficiency under recent crises: Asia-Pacific focus. Working paper. Available at SSRN: http://ssrn.com/abstract=1913995.

[2] Al-Khazali O.M., Leduc G. and Pyun C.S. (2011). Market efficiency of floating exchange rate systems: Some evidence from Pacific-Asian countries. Global Finance Journal, forthcoming.

[3] Al-Khazali O.M., Pyun C.S. and Kim D. (2012). Are exchange rate movements predictable in Asia-Pacific markets? Evidence of random walk and martingale difference processes. International Review of Economics and Finance, 21, 221231.

[4] Andrews D.W.K. (1991). Heteroskedasticity and autocorrelation consistent covariance matrix estimation. Econometrica, 58, 817-858.

[5] Andrews D.W.K. and Ploberger W. (1996). Testing for serial correlation against an $\operatorname{ARMA}(1,1)$ process. Journal of the American Statistical Association, 91, $1331-1342$.

[6] Beine M., De Grauwe P. and Grimaldi M. (2009). The impact of FX central bank intervention in a noise trading framework. Journal of Banking and Finance, 33, 1187-1195.

[7] Belaire-Franch J. and Contreras D. (2004). Ranks and signs-based multiple variance ratio tests. Working paper, Department of Economic Analysis, University of Valencia.

[8] Belaire-Franch J. and Contreras D. (2011). Testing the martingale property of exchange rates: A replication. Studies in Nonlinear Dynamics and Econometrics, $15,1-17$.

[9] Belaire-Franch J. and Opong K.K. (2005). Some evidence of random walk behaviour of Euro exchange rates using ranks and signs. Journal of Banking and Finance, 29, 1631-1643. 
[10] Belaire-Franch J. and Opong K.K. (2010). Testing for random walk in euro exchange rates using the subsampling approach. Applied Economics Letters, 17, $1145-1151$.

[11] Box G. and Pierce D. (1970). Distribution of residual autocorrelations in autorregressive integrated moving average time series models. Journal of American Statistical Association, 65, 1509-1527.

[12] Chang Y. (2004). A re-examination of variance-ratio test of random walks in foreign exchange rates. Applied Financial Economics, 14, 671-79.

[13] Charles A. and Darné O. (2009a). Variance ratio tests of random walk: An overview. Journal of Economic Surveys, 23, 503-527.

[14] Charles A. and Darné O. (2009b). Testing for random walk behavior in Euro exchange rates. International Economics, 119, 25-45.

[15] Charles A., Darné O. and Kim J.H. (2011). Small sample properties of alternative tests for martingale difference hypothesis. Economics Letters, 110, 151-154.

[16] Chen W.W. and Deo R.S. (2006). The variance ratio statistic at large horizons. Econometric Theory, 22, 206-234.

[17] Chiang S-M., Lee Y-H., Su H-M. and Tzou Y-P. (2010). Efficiency tests of foreign exchange markets for four Asian countries. Research in International Business and Finance, 24, 284-294.

[18] Choi I. (1999). Testing the random walk hypothesis for real exchange rates. Journal of Applied Econometrics 14, 293-308.

[19] Chortareas G., Jiang Y. and Nankervis J.C. (2011). The random-walk behavior of the Euro exchange rate. Finance Research Letters, 7, 158-162.

[20] Chow K.V. and Denning K.C. (1993). A simple multiple variance ratio test. Journal of Econometrics, 58, 385-401.

[21] Chuluun T., Eun C.S. and Kilic R. (2011). Investment intensity of currencies and the random walk hypothesis: Cross-currency evidence. Journal of Banking and Finance, 35, 372-387.

[22] Deo R.S. (2000). Spectral tests of the martingale hypothesis under conditional heteroskedasticity. Journal of Econometrics, 99, 291-315. 
[23] Diamandis P.F., Kouretas G.P. and Zarangas L. (2007). Dual foreign currency markets and the role of expectations: Evidence from the Pacific Basin countries. Research in International Business and Finance, 21, 238-259.

[24] Dominguez K.M. (1990). Market responses to coordinated central bank intervention. Carnegie-Rochester Conference Series on Public Policy, 32, 121-163.

[25] Dominguez K.M. (1998). Central bank intervention and exchange rate volatility. Journal of International Money and Finance, 17, 161-190.

[26] Dominguez K.M. (2003). The market microstructure of central bank intervention. Journal of International Economics, 59, 25-45.

[27] Dominguez K.M. (2006). When do central bank interventions influence intradaily and longer-term exchange rate movements? Journal of International Money and Finance, 25, 1051-1071.

[28] Dominguez K.M. and Frankel J.A. (1993). Does Foreign-exchange intervention matter? The portfolio effect. The American Economic Review, 83, 1356-1369.

[29] Domínguez M.A. and Lobato I.N. (2003). A consistent test for the martingale difference hypothesis. Econometric Reviews, 22, 351-377.

[30] Durlauf S. (1991). Spectral-based test for the martingale hypothesis. Journal of Econometrics, 50, 1-19.

[31] Enders W. and Ma J. (2011) Sources of the great moderation: A time-series analysis of GDP subsectors. Journal of Economic Dynamics and Control, 35, $67-79$.

[32] Engle R.F. (1982). Autoregressive conditional heteroscedasticity with estimates of the variance of United Kingdom inflations. Econometrica, 50, 987-1007.

[33] Escanciano J.C. and Lobato I.N. (2009a). An automatic portmanteau test for serial correlation. Journal of Econometrics, 151, 140-149.

[34] Escanciano J.C. and Lobato I.N. (2009b). Testing the Martingale Hypothesis. In Patterson K. and Mills T.C. (eds) Palgrave Hand-book of Econometrics, Palgrave, MacMillan.

[35] Escanciano J.C. and Velasco C. (2006). Generalized spectral tests for the martingale difference hypothesis. Journal of Econometrics, 134, 151-185. 
[36] Fama E. (1965). The behaviour of stock market prices. Journal of Business, 38, 34-105.

[37] Fama E. (1970). Efficient capital markets: A review of theory and empirical work. Journal of Finance, 25, 383-417.

[38] Fong W.M. and Ouliaris S. (1995). Spectral tests of the martingale hypothesis for exchange rates. Journal of Applied Econometrics, 10, 255-271.

[39] Fong W.M., Koh S.K. and Ouliaris S. (1997). Joint variance-ratio tests of the martingale hypothesis for exchange rates. Journal of Business and Economic Statistics, 15, 51-59.

[40] Fratzscher M. (2006). On the long-run effectiveness of exchange rate communication and interventions. Journal of International Money and Finance, 25, 146167.

[41] Gali J. and Gambetti L. (2009). On the sources of the Great Moderation. American Economic Journal: Macroeconomics, 1, 26-57.

[42] Hansen P.R. (2003). A test for superior predictive ability. Journal of Business and Economic Statistics, 23, 365-380.

[43] Hong Y. (1996). Consistent testing for serial correlation of unknown form. Econometrica, 64, 837-864.

[44] Hong Y. (1999). Hypothesis testing in time series via the empirical characteristic function: A generalized spectral density approach. Journal of the American Statistical Association, 94, 1201-1220.

[45] Hong Y. and Lee T.H. (2003). Inference on predictability of foreign exchange rate changes via generalized spectrum and nonlinear time series models. Review of Economics and Statistics, 85, 1048-1062.

[46] Hong Y. and Lee Y.J. (2005). Generalized spectral tests for conditional mean models in time series with conditional heteroskedasticity of unknown form. Review of Economic Studies, 72, 499-541.

[47] Hoque H.A.A.B., Kim J.H. and Pyun C.S. (2007). A comparison of variance ratio tests of random walk: A case of Asian emerging stock markets. International Review of Economics and Finance, 16, 488-502. 
[48] Horowitz J.L., Lobato I.N., Nankervis J.C. and Savin N.E. (2006). Bootstrapping the Box-Pierce $Q$ test: A robust test of uncorrelatedness. Journal of Econometrics, $133,841-862$.

[49] Hsieh D. (1988). The statistical property of daily foreign exchange rates: 19741983. Journal of International Economics, 24, 129-145.

[50] Hsu P.-O. and Kuan K.-C. (2005). Reexamining profitability of technical analysis with data snooping checks. Journal of Financial Econometrics, 3, 606-628.

[51] Jeon B.N. and Lee E. (2002). Foreign exchange market efficiency, cointegration, and policy coordination. Applied Economics Letters, 9, 61-68.

[52] Jeon B.N. and Seo B. (2003). The impact of the Asian financial crisis on foreign exchange market efficiency: The case of East Asian countries. Pacific-Basin Finance Journal, 11, 509-525.

[53] Kim, C.-J., Morley J. and Piger J. (2008). Bayesian counter factual analysis of the sources of the Great Moderation. Journal of Applied Econometrics, 23, 173-191.

[54] Kim J.H. (2006). Wild bootstrapping variance ratio tests. Economics Letters, 92, $38-43$.

[55] Kim J.H. (2009). Automatic variance ratio test under conditional heteroskedasticty. Finance Research Letters, 3, 179-185.

[56] Kim J.H. and Shamsuddin A. (2008). Are Asian stock markets efficient? Evidence from new multiple variance ratio tests. Journal of Empirical Finance, $15,518-532$.

[57] Kim J.H., Lim K.P. and Shamsuddin A. (2011). Stock return predictability and the adaptive markets hypothesis: Evidence from century long U.S. Data. Journal of Empirical Finance, 18, 868-879.

[58] Kuan C-M. and Lee W. (2004). A new test of the martingale difference hypothesis. Studies in Nonlinear Dynamics and Econometrics, 8, 1-24.

[59] LeBaron B. (1999). Technical trading rule profitability and foreign exchange intervention. Journal of International Economics, 49, 125-143.

[60] Lim K.P. and Brooks R.D. (2010). The evolution of stock market efficiency over time: A survey of the empirical literature. Journal of Economic Surveys, 24, $1-$ 40. 
[61] Liu C.Y. and He J. (1991). A variance ratio test of random walks in foreign exchange rate. Journal of Finance, 46, 773-785.

[62] Ljung G.M. and Box G.E.P. (1978). On a measure of lack of fit in time series models. Biometrika, 65, 297-303.

[63] Lo A.W. (2004). The adaptive markets hypothesis: Market efficiency from an evolutionary perspective. Journal of Portfolio Management, 30, 15-29.

[64] Lo A.W. (2005). Reconciling efficient markets with behavioral finance: The adaptive markets hypothesis. Journal of Investment Consulting, 7, 21-44.

[65] Lo A.W. and MacKinlay A.C. (1988). Stock market prices do not follow random walk: Evidence from a simple specification test. The Review of Financial Studies, 1, 41-66.

[66] Lo A.W. and MacKinlay A.C. (1989). The size and power of the variance ratio test in finite samples: A Monte Carlo investigation. Journal of Econometrics, 40, 203-238.

[67] Lobato I.N., Nankervis J.C. and Savin N.E. (2001). Testing for autocorrelation using a modified Box-Pierce Q test. International Economic Review, 42, 187205.

[68] Lobato I.N., Nankervis J.C. and Savin N.E. (2002). Testing for zero autocorrelation in the presence of statistical dependence. Econometric Theory, 18, 730-743.

[69] Meese R.A. and Rogoff K. (1983). Empirical exchange rate models of the Seventies: Do they fit out of sample? Journal of International Economics, 14, $3-24$.

[70] Melvin M. (2004). International Money and Finance. Pearson Addison-Wesley, Boston.

[71] Melvin M. and Taylor M.P. (2009). The crisis in the foreign exchange market. Journal of International Money and Finance, 28, 1317-1330.

[72] Menkhoff L. (2010). High-frequency analysis of foreign exchange interventions: What do we learn? Journal of Economic Surveys, 24, 85-112.

[73] Nankervis J.C. and Savin N.E. (2010). Testing for serial correlation: Generalized Andrews-Ploberger tests. Journal of Economic and Business Statistics, 28, 246255. 
[74] Neely C.J. (2002). The temporal pattern of trading rule returns and exchange rate intervention: Intervention does not generate technical trading rule profits. Journal of International Economics, 58, 211-232.

[75] Neely C.J., Weller P.A. and Ulrich J.M. (2009). The adaptive markets hypothesis: Evidence from the foreign exchange market. Journal of Quantitative and Financial Analysis, 44, 467-488.

[76] Richardson M. and Smith T. (1991). Tests of financial models in the presence of overlapping observations. Review of Financial Studies, 4, 227-254.

[77] Samuelson P.A. (1965). Proof that properly anticipated prices fluctuate randomly. Industrial Management Review, 6, 41-9.

[78] Simon H.A. (1955). A behavioral model of rational choice. The Quarterly Journal of Economics, 69, 99-118.

[79] Smith G., Jefferis K. and Ryoo, H.-J. (2002). African stock markets: Multiple variance-ratio tests of random walks. Applied Financial Economics, 12, 475484.

[80] Szakmary A. and Mathur I. (1997). Central bank intervention and trading rule profits in foreign exchange markets. Journal of International Money and Finance, $16,513-536$.

[81] Whang Y.-J. and Kim J. (2003). A multiple variance ratio test using subsampling. Economics Letters, 79, 225-30.

[82] White H. (2000). A reality check for data snooping, Econometrica, 68, 10971126.

[83] Wright J.H. (2000). Alternative variance-ratio tests using ranks and signs. Journal of Business and Economic Statistics, 18, 1-9.

[84] Yilmaz K. (2003) Martingale property of exchange rates and central bank intervention. Journal of Business and Economic Statistics, 21, 383-395. 